\title{
Performance Evaluation of Refrigeration Units in Natural Gas Liquid Extraction Plant
}

\author{
Awajiogak Anthony Ujile and Dirina Amesi \\ Department of Chemical/Petrochemical Engineering, Faculty of Engineering, Rivers State University of Science and Technology, \\ PMB 5080, Port Harcourt 50000, Nigeria
}

Correspondence should be addressed to Awajiogak Anthony Ujile; ogakujile@yahoo.com

Received 29 December 2013; Accepted 23 February 2014; Published 25 March 2014

Academic Editor: Ahmet Z. Sahin

Copyright (C) 2014 A. A. Ujile and D. Amesi. This is an open access article distributed under the Creative Commons Attribution License, which permits unrestricted use, distribution, and reproduction in any medium, provided the original work is properly cited.

\begin{abstract}
This paper has applied thermodynamics principles to evaluate the reliability of $390 \mathrm{~m}^{3} / \mathrm{hr}$ natural gas processing plant. The thermodynamics equations were utilized in the evaluation, characterization, and numerical simulation of key process parameters in natural gas liquid extraction plant. The results obtained show the comparison of the coefficient of performance, compression ratio, isentropic work, actual work, electrical power requirements, cooling water consumption in intercoolers, compressor power output, compressor capacity, and isentropic, volumetric, and mechanical efficiency of the two-stage refrigeration unit with a flash gas economizer and these were compared with the designed specifications. The second law of thermodynamics was applied in analyzing the refrigeration unit and the result shows that exergetic losses or lost work due to irreversibility falls within operating limit that is less than $1.0 \%$. Similarly, the performance of expansion turbine (expander) parameters was monitored and the results indicate a considerable decrease in turbine efficiencies as the inlet gas pressure increases resulting in an increased power output of the turbine leading to a higher liquefaction rate.
\end{abstract}

\section{Introduction}

The production and availability of natural gas liquid depend largely on the supply of raw natural gas from production wellhead and the operating conditions of the process unit that make up the extraction plant. Most gas processing plants are faced with problems ranging from inadequate supply, poor facility performance, and human factors. These problems can lead to low productivity of natural gas liquids and reduction in gas quality which could result in shutting down of the plant. Poor facilities such as inadequate electricity supply and processed water supply used in process equipment also lead to intermittent operations and malfunction of process equipment such as pumps, compressors, and valves if they are not adequately checked.

Human factors may also result from the inability of gas plant operators to monitor thermodynamics parameters such as the pressure, flow rates, and temperature on process equipment which could result in loss of data in control room and unintended activation or deactivation of process devices and reduce the plant efficiency. In spite of the fact that these thermodynamics parameters are monitored daily in a gas plant, there are problems of low gas feed inlet pressure and insufficient gas flow rate. These have resulted in low volume of natural gas liquids produced, the extracted natural gas liquids not attaining the expected cryogenic temperature requirement, and variation in gas quality discharging from the outlet of natural gas liquid extraction unit bottom product.

If the available inlet gas pressure is low, it can result in compressor system suction pressure falling below atmospheric pressure. This can also lead to air leakages into the compressor system, contributing to pulsation, corrosion, and low heating value of natural gas. In order to solve these problems, performance evaluation of the process units in natural gas liquids extraction using thermodynamics principles is necessary to ensure that these problems are minimized.

It is seen from literature survey that several papers have been published focusing on thermodynamic analysis of a gas turbine power plant.

Rahman et al. [1] and Taniguchi and Miyamae [2] carried out the study on the effects of ambient temperature and ambient pressure as well as temperature of exhaust gases on 
performance of gas turbine. Khaliq and Kaushik [3] studied the efficiency of a gas turbine cogeneration system with heat recovery steam generator.

Keith and Kenneth [4] developed a new method of applying overall plant material balance equation to determine the performance of a natural gas processing plant. Jibril et al. [5] studied the simulation of expansion turbine (expander) for recovery of natural gas liquids from natural gas stream gas using HYPRO TECH's HYSYS process simulation software. Donnelly et al. [6] carried out researches on process simulation and optimization of cryogenic operations using multistream brazed aluminum heat exchangers. Ganapathy et al. [7] studied the energy analysis of operating lignite fired thermal power plant. Design methodology for parametric study and thermodynamic performance evaluation of natural gas process plant has been developed. Refrigeration unit and expansion turbine unit which are the major components of the plant were evaluated. The expansion of natural gas through an expansion turbine with efficiencies shows a very good performance Ujile and Alawa [8]. The comparison between the energy losses and the energy losses of the components unit were investigated.

This paper examined the reliability of a gas plant which is the ability of a plant to maintain a stable efficiency with respect to time using thermodynamics equations.

\section{Methodology/System Descriptions}

2.1. Propane Refrigeration Unit. The simulation of process units in propane refrigeration cycle involves the applications of thermodynamics principles to the following.

(i) Calculate the amount of heat added to or removed from process streams.

(ii) Estimate the power requirements for process equipment such as pumps, compressors, and turbine.

(iii) Evaluate the performance of a flash separator at various temperatures and pressures.

(iv) Determine the bubble and dew point temperature associated with distillation and bottom products.

A systematic diagram of propane refrigeration cycle is shown in Figure 1. The refrigerant passes through the scrubber into the first stage compressor at 1.9 bar as saturated vapor where it mixes up with the vapor from the economizer unit. It is compressed to the inlet of the second stage compressor at $2.5 \mathrm{bar}$ and discharges at $5.0 \mathrm{bar}$ into the condenser as superheated vapor. It leaves the condenser at $4.7 \mathrm{bar}$ and enters the first expansion valve and from the expansion valve into an economizer drum where it flashes at an intermediate pressure of $3.3 \mathrm{bar}$. The vapour phase with the economizer at the top mixes up the vapour from the first stage compressor, while the liquid discharges at the bottom and enters the second expansion valve into the chiller at a pressure of 2.5 bar. The process gas (natural gas) flows inside the tubes connected to the chiller at $41^{\circ} \mathrm{C}$ and countercurrently exchanges heat and gives up its energy with the liquid refrigerant surrounding the tubes. The refrigerant boils up and leaves the chiller space as saturated vapor to be recompressed again.
2.2. Expansion Turbine Unit. A turbo expander or an expansion turbine is a centrifugal or axial flow turbine through which a high pressure gas is expanded to produce useful work that is used to drive a compressor. Because work is extracted from the expanding high pressure gas, the expansion is an approximation by an isentropic process (a constant entropy process).

In the process of producing work, the expander lowers the bulk stream temperature which could result in partial liquefaction of the bulk stream (natural gas).

A systematic diagram of an expansion turbine (expander) is presented in Figure 2. The feed gas enters the gas treating unit after which it is cooled firstly in a gas-to-gas heat exchanger and secondly the propane chiller. The condensed liquid is removed in a separator and the gas from the separator is cooled further in the low temperature gas-to-gas heat exchanger and fed into a second cooled separator. Gas from the cooled separator expands through the expansion turbine to the pressure at the top of the demethanizer which varies from 100 to 450 bar. During the expansion, condensate is formed and the expander lowers the pressure of the inlet gas value to the demethanizer pressure of the range 100-450 bar.

Thermodynamics Performance Parameters of Propane Refrigeration Unit. The relevant parameters required for thermodynamics performance evaluation of propane refrigeration of natural gas may be considered as follows.

Coefficient of Performance. This is defined as the ratio of the heat absorbed $\left(Q_{\text {in }}\right)$ by the refrigerant while passing through the chiller to the work input $\left(W_{\text {in }}\right)$ required compressing the refrigerant in the compressor. This is mathematically expressed as $[9,10]$

$$
\mathrm{COP}=\frac{Q_{\text {in }}}{W_{\text {in }}},
$$

but

$$
\begin{aligned}
W_{\text {in }} & =W_{\text {comp1 }}+W_{\text {comp2 }} \\
& =\left(1-X_{G}\right)\left(H_{B}-H_{A}\right)+M_{C}\left(H_{E}-H_{D, \text { MIX }}\right), \\
\mathrm{COP} & =\frac{\left(1-X_{G}\right) M_{C}\left(H_{A}-H_{I}\right)}{\left(1-X_{G}\right)\left(H_{B}-H_{A}\right)+M_{C}\left(H_{E}-H_{D, \mathrm{MIX}}\right)} .
\end{aligned}
$$

Refrigeration Capacity. The refrigeration capacity determines the rate of circulation of the refrigerant which, in turn, determines the design and size of various units such as condenser, compressor, evaporator (chiller), and expansion valves. This is expressed by the following equation:

$$
R_{c}=\frac{M_{C}\left(H_{A}-H_{I}\right)}{210} \mathrm{KJ} / \mathrm{min} .
$$

The mass flow rate of cooling water is calculated as follows:

$$
M_{\mathrm{CW}}=\frac{Q}{C p_{\mathrm{CW}} \Delta T} .
$$

The overall performance of a compressor is affected mainly by the inlet pressure and the interstage cooler efficiency. 


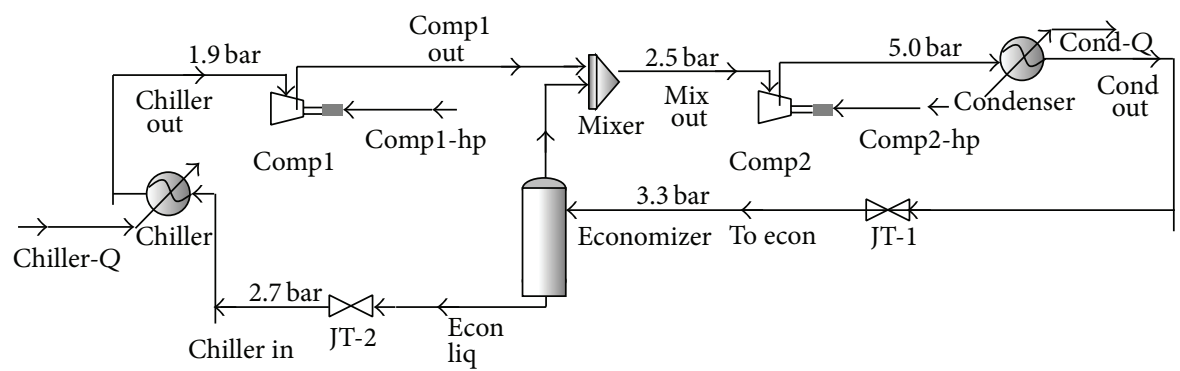

FIGURE 1: Process flow diagram of propane refrigeration of natural gas with application of Hysys software.

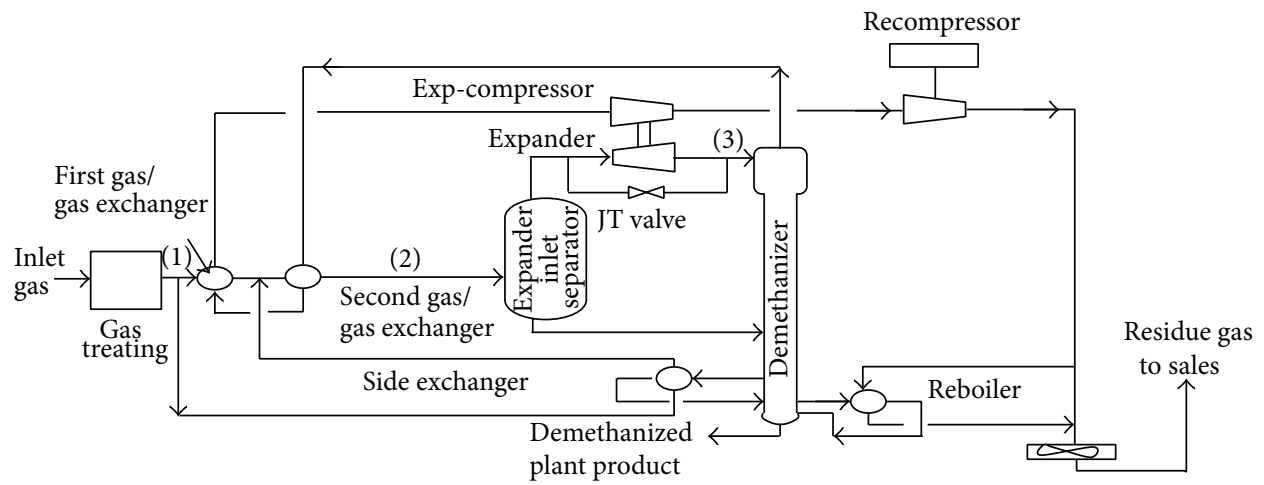

FIGURE 2: Flow diagram of expander process.

The simulation of process units in propane refrigeration resulted in loss of energy on the system. The second availability balance was applied to calculate the energy losses or lost work due to irreversibility of the process. The thermodynamics equations applied on each of the process units are as follows [10].

Compressor unit:

$$
L_{W}=M_{C}\left[\left(H_{A}-T_{o} S_{A}\right)\right]-\left(H_{B}-T_{o} S_{B}\right)-W_{E} ;
$$

condenser unit:

$$
\begin{aligned}
L_{W} & =T_{o}\left[M_{C}\left(S_{C}-S_{B}\right)\right]+M_{\mathrm{CW}} S_{\mathrm{CW}(\text { out })}-S_{\mathrm{CW}(\text { in })}, \\
M_{\mathrm{CW}} & =M_{\mathrm{C}}\left[\frac{H_{E}-H_{F}}{H_{\mathrm{CW}(\text { out })}-H_{\mathrm{CW}(\text { in })}}\right] ;
\end{aligned}
$$

expansion valve:

$$
\begin{aligned}
& L_{W}=M_{C} T_{o}\left(S_{B}-S_{C}\right), \\
& L_{W}=M_{C} T_{o}\left[\left(S_{A}-S_{D}\right)-\left(\frac{H_{A}-H_{D}}{T_{i}}\right)\right] .
\end{aligned}
$$

Refrigerant chiller: the chiller is the unit where the process gas (natural gas) gives up its energy to the liquid refrigerant. The refrigerating effect which is the amount of heat absorbed by refrigerant or removed from the refrigerated space is expressed as

$$
Q_{\text {in }}=\left(1-X_{G}\right) M_{C}\left(H_{A}-H_{I}\right) .
$$

The fraction of refrigerant vaporized in the chiller is determined from enthalpy balance as follows:

$$
M_{C}\left(H_{H}\right)_{L}=M_{C} X_{V}\left(H_{I}\right)+M_{C}\left(1-X_{v}\right)\left(H_{I}\right)_{L}
$$

where $X_{v}$ is the mole fraction of refrigerant that evaporates as it throttles to the economizer unit.

Expansion Turbine Unit. The relevant thermodynamics parameters applied in expansion turbine unit in a gas plant are as follows.

(i) Isentropic Turbine Efficiency. This is defined as the ratio of turbine actual work output to the work output that would be achieved if the process between the inlet and outlet pressure was isentropic. By definition [11],

$$
\eta_{E}=\frac{h_{1}-h_{2 a}}{h_{1}-h_{2, S}}
$$

(ii) Isentropic and Actual Work. The isentropic work of a turbine is the work done by the turbine during the constant entropy whereas actual work is the gross work of a turbine:

$$
\begin{gathered}
W_{\mathrm{act}}=m\left(h_{2}-h_{1}\right), \\
W_{\mathrm{is}}=-m\left(h_{1}-h_{2, S}\right) .
\end{gathered}
$$




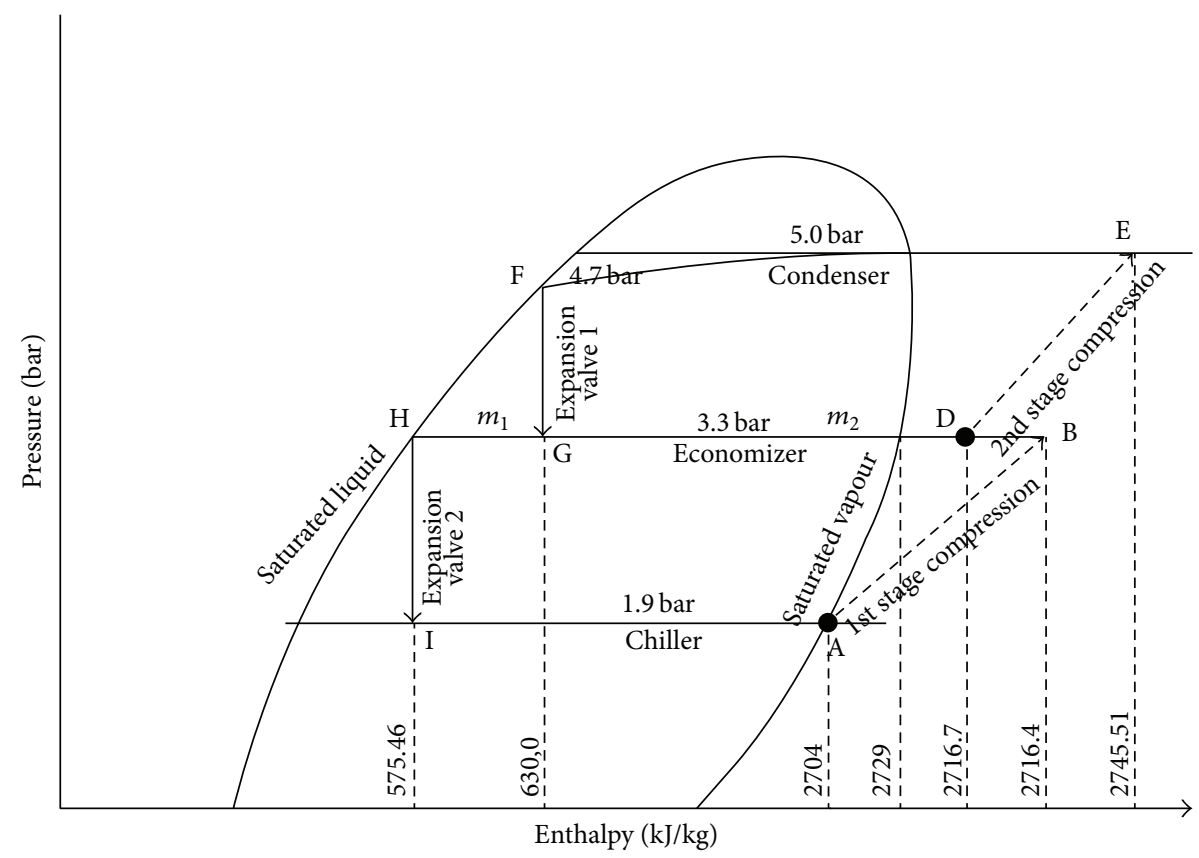

FIgURE 3: Pressure enthalpy diagram of a propane refrigeration cycle.

(iii) Power Recovery. The expander gas power recovery is the output power of the turbine list to drive the compressor. By definition,

$$
P_{g}=-\eta_{m}\left(h_{1}-h_{2, S}\right) \text {. }
$$

(iv) Theoretical and Actual Discharge Temperature. The discharge and actual temperatures of a turbine are expressed by the following equations [11, 12]:

$$
\begin{gathered}
T_{2}^{\prime}=T_{1}\left(\frac{p_{2}}{p_{1}}\right)^{(k-1) / k}, \\
T_{2}=T_{1}+T_{1}\left[\left(\frac{p_{2}}{p_{1}}\right)^{(K-1) / K}-1\right] \eta_{E} .
\end{gathered}
$$

The results obtained from the evaluation with the above equations are shown in graphical form in Figures 3 and 4.

\section{Results and Discussion}

The results on the refrigeration unit of a gas plant were obtained using the $P-S$ and $T-S$ diagrams.

The two-stage compression refrigeration system in Figures 3 and 4 operates with a pressure range of 1.9 and 5.0 bar. The refrigerant enters the first stage compressor at a suction pressure of 1.9 bar with enthalpy and entropy values of $2704 \mathrm{KJ} / \mathrm{kg}$ and $7.145 \mathrm{KJ} / \mathrm{kg} \cdot \mathrm{K}$, respectively. It discharges into a mixer where it mixes up with the vapor leaving the top of the flash economizer. The refrigerant is compressed to the second stage compressor operating with a suction pressure of 2.5 bar with enthalpy and entropy values of $2716.4 \mathrm{KJ} / \mathrm{kg}$ and $7.052 \mathrm{KJ} / \mathrm{kg} \cdot \mathrm{K}$, respectively, and discharges at the condenser inlet pressure of $5.0 \mathrm{bar}$, where $-17,386.7 \mathrm{~J} / \mathrm{kg}$ of heat is rejected to the surrounding. The enthalpy and entropy values of the condenser as a saturated vapour at a pressure of 4.7 bar were observed to be $630 \mathrm{KJ} / \mathrm{kg}$ and $1.8363 \mathrm{KJ} / \mathrm{kg} \cdot \mathrm{K}$, respectively. The refrigerant is throttled to a flash economizer at an intermediate pressure of 3.3 bar. During flashing $0.0034 \mathrm{~kg} / \mathrm{s}$ of vapor evaporates from the economizer drum while $0.1305 \mathrm{~kg} / \mathrm{s}$ of liquid is throttled to the chiller at a pressure of 1.9 bar with enthalpy and entropy values of $575.5 \mathrm{KJ} / \mathrm{kg}$ and $1.8545 \mathrm{KJ} / \mathrm{kg} \cdot \mathrm{K}$, respectively. The process gas (natural gas) countercurrently exchanges heat and gives up its energy to the liquid refrigerant at a temperature of $41^{\circ} \mathrm{C}$. The result of the two-stage compression refrigeration is summarized in Table 1.

The process parameters of other auxiliary units in propane refrigeration plant are shown in Table 2.

The energy balance of the propane refrigeration unit obtained from the evaluation based on the equations highlighted for the analysis is shown in Table 3.

By the design conditions, the centrifugal compressors used in compressing the refrigerant should operate with a pressure ratio of $1.2: 1$ and $1.4: 1$, isentropic efficiency of $70-80 \%$, volumetric efficiency of $60-89 \%$, and mechanical efficiency of $20-50 \%$. By analytical method, the pressure ratio was found to be 1.316 and 1.414; the isentropic efficiency was found to be $48.56 \%$ and $51.97 \%$; the volumetric efficiency was found to be $55.0 \%$ and $46.7 \%$ for the first and second stage compressors, respectively, while the mechanical efficiencies are $57.7 \%$ and $46.51 \%$, respectively. The refrigeration cycle was operating with an overall coefficient of performance of 62.37 with a refrigerating capacity of $4,922.2$ tons after examining the performance of other auxiliary units within the systems. Tables 1, 2, and 3 show values obtained from the evaluation. 


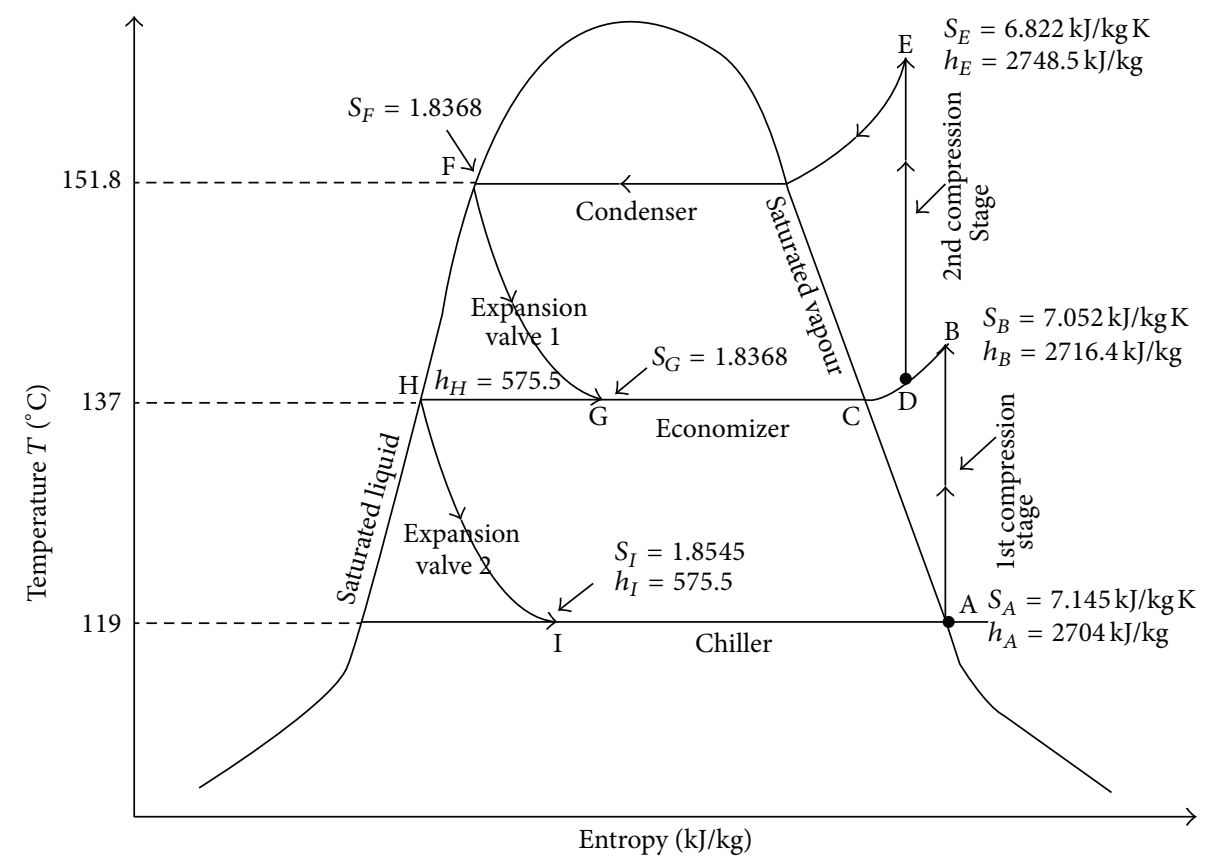

FIgURE 4: Temperature entropy diagram of a propane refrigeration cycle.

TABLE 1: Summary of two-stage compression refrigeration.

\begin{tabular}{lccc}
\hline Parameters & Units & 1st stage compressor & 2nd stage compressor \\
\hline Suction pressure & bar & 1.9 & 2.5 \\
Discharge pressure & bar & 2.5 & 5.0 \\
Compression ratio & - & 1.316 & 1.414 \\
Isentropic work of compression & $\mathrm{J} / \mathrm{kg}$ & $20,644.25$ & $22,094.91$ \\
Actual work of compression & $\mathrm{J} / \mathrm{kg}$ & $20,644.25$ & $21,872.85$ \\
Isentropic efficiency & $\%$ & 48.56 & 51.98 \\
Mechanical efficiency & $\%$ & 20.71 & 46.51 \\
Volumetric efficiency & $\%$ & 55.0 & 46.7 \\
Actual power requirement & $\mathrm{KW}$ & 0.0969 & 0.0960 \\
Cooling water consumption in intercoolers & $\mathrm{m}^{3} / \mathrm{s}$ & 7.2612 & 19.282 \\
Compressor capacity & $\mathrm{m}^{3} / \mathrm{s}$ & 2.1566 & 2.1096 \\
Work input in comp 1 and comp 2 & $\mathrm{J} / \mathrm{kg}$ & 273.14 & 273.14 \\
Work output & $\mathrm{J} / \mathrm{kg}$ & 1197.89 & 2414.11 \\
\hline
\end{tabular}

The Kelvin-Planck statement of the second law of thermodynamics tells us that it is impossible to have a heat engine that will convert all the heat received from the high temperature source, $Q_{H}$, into useful work in a thermodynamic cycle. It is necessary to reject part of the received heat to the low temperature source, $Q_{L}$. In other words, it is impossible to have a $100 \%$ efficiency heat engine as corroborated by Kumar et al. [13] and José and Simões-Moreira [14].

\section{Conclusion}

The thermodynamics equations were applied to construct Figures 3 and 4 which determine the performance of the plant. The recorded efficiencies ranging from $63.92 \%$ to $77 \%$ have shown that the overall performance has deviated from the design efficiency. This condition may increase the operational cost of the plant.
The following recommendations are highlighted to ensure optimum efficiency and reliability of NGL plant.

(i) The feed gas must be free from $\mathrm{CO}_{2}$ and water. This affects plant efficiency and operations if not properly checked by freezing the fittings, valves, and other associated equipment.

(ii) The inlet strainer differential pressure must not be high; otherwise the expander will trip off on high differential pressure.

(iii) The refrigeration unit must be operated within the operating and design conditions to avoid overfreezing or warming of the demethanizer column.

(iv) There is need for proper insulation of piping system within the NGL extraction plant. The reason is not to allow the surrounding heat to enter the system, 
TABLE 2: Process parameters of other auxilliary units.

\begin{tabular}{|c|c|c|c|c|c|c|}
\hline Parameters & Unit & Condenser & Economizer & Expansion valve 1 & Expansion valve 2 & Refrigerant chiller \\
\hline Suction pressure & bar & 5.0 & 3.3 & 4.7 & 3.3 & 2.3 \\
\hline Discharge pressure & bar & 4.7 & - & 3.3 & 1.9 & 1.9 \\
\hline Heat load & $\mathrm{J} / \mathrm{kg}$ & $-17,386.7$ & 5733.78 & - & - & $17,036.04$ \\
\hline $\begin{array}{l}\text { Mass flow rate of } \\
\text { vapor-economizer }\end{array}$ & $\mathrm{kg} / \mathrm{s}$ & - & 0.0034 & - & - & - \\
\hline $\begin{array}{l}\text { Mass flow rate of } \\
\text { liquid-economizer }\end{array}$ & $\mathrm{kg} / \mathrm{s}$ & - & 0.1305 & - & - & - \\
\hline $\begin{array}{l}\text { Mass flow rate of cooling } \\
\text { water-condenser }\end{array}$ & $\mathrm{kg} / \mathrm{s}$ & 6.72 & - & - & - & - \\
\hline Joule Thompson coefficient & - & - & - & 8.57 & 12.86 & - \\
\hline $\begin{array}{l}\text { Mole fraction of liquid remaining } \\
\text { in chiller }\end{array}$ & - & & & & 0.035 & 0.00014 \\
\hline $\begin{array}{l}\text { Mole fraction of vapor } \\
\text { evaporated in chiller }\end{array}$ & - & & 0.025 & 0.025 & - & 0.045 \\
\hline $\begin{array}{l}\text { Mass flow rate of } \\
\text { liquid-condenser accumulator }\end{array}$ & $\mathrm{kg} / \mathrm{s}$ & 0.1339 & & & & \\
\hline
\end{tabular}

TABLE 3: Energy balance propane refrigeration unit.

\begin{tabular}{lccc}
\hline Process units & Energy gain $(\mathrm{KJ} / \mathrm{kg})$ & Energy lost $(\mathrm{KJ} / \mathrm{kg})$ & \% of lost work \\
\hline Compressor 1 & 12.30 & -334.28 & -0.015 \\
Compressor 2 & 32.11 & -501.45 & -0.023 \\
Condenser & - & 12483.89 & 0.06 \\
Expansion valve JT-1 & - & 12495.54 & 0.06 \\
Expansion valve JT-2 & - & -1435547.8 & 6.62 \\
Economizer drum & 5733.78 & - & - \\
Refrigerant chiller & 17036.04 & -1242710.43 & -5.73 \\
\hline Total & 22814.23 & 216981.07 & 0.972 \\
\hline
\end{tabular}

thereby warming the system, and there may be freezing out of the plant.

(v) Proper sizing of the process line using the various line balance methods to compare the amount of natural gas entering the process plant with the amount put in should be adopted at the design stage of the process plant.

\section{Nomenclature}

$C p_{\mathrm{CW}}$ :

The specific heat capacity of water

$H_{A}, H_{B}, H_{D \text {,mix }}, H_{E}$ and $H_{I}$ : The enthalpies of refrigerant at compressor inlet $(\mathrm{KJ} / \mathrm{kg})$, outlet $(\mathrm{KJ} / \mathrm{kg})$, vapor mixture coming from compressor and economizer units $(\mathrm{KJ} / \mathrm{kg})$, at the condenser inlet $(\mathrm{KJ} / \mathrm{kg})$, and at the inlet of the refrigerant chiller $(\mathrm{KJ} / \mathrm{kg})$, respectively

$h_{1}, h_{2 a}, h_{2, S}:$
The enthalpies of the gas expander inlet, gas expander outlet, and at the exit pressure but at the inlet entropy $(\mathrm{KJ} / \mathrm{kg})$, respectively $k$ :

$L_{w}$ :

$m:$

$M_{c}$ :

$M_{\mathrm{CW}}$ :

$P_{1}$ and $P_{2}$ :

Q:

$S_{A}, S_{B}, S_{C}, S_{D}$ : The entropies of refrigerant at compressor inlet $(\mathrm{KJ} / \mathrm{kg} \cdot \mathrm{K})$, compressor outlet $(\mathrm{KJ} / \mathrm{kg} \cdot \mathrm{K})$, leaving the economizer $(\mathrm{KJ} / \mathrm{kg} \cdot \mathrm{K})$, and vapor mixture $(\mathrm{KJ} / \mathrm{kg} \cdot \mathrm{K})$, respectively

$S_{\mathrm{CW}(\mathrm{in})}, S_{\mathrm{CW}(\text { out })}$ : The entropies of inlet cooling water and outlet cooling water, respectively

$T_{o}: \quad$ The dead state temperature 
$T_{1}$ : The inlet gas temperature to expander $\left({ }^{\circ} \mathrm{C}\right)$

$T_{2}$ : The actual gas temperature at expander outlet $\left({ }^{\circ} \mathrm{C}\right)$

$T_{2}^{\prime}$ : The theoretical gas temperature at expander outlet $\left({ }^{\circ} \mathrm{C}\right)$

$W_{E}$ : The electrical power requirement to compressor (KW)

$X_{G}$ : The mole fraction of vapor leaving the economizer unit

$\Delta T$ : The temperature difference within the system boundary

$\eta_{E}$ : The expander efficiency

$\eta_{m}$ : The mechanical efficiency.

\section{Conflict of Interests}

The authors declare that there is no conflict of interests regarding the publication of this paper.

\section{References}

[1] M. M. Rahman, T. K. Ibrahim, K. Kadirgama, R. Mamat, and R. A. Bakar, "Influence of operation conditions and ambient temperature on performance of gas turbine power plant," Advanced Materials Research, vol. 189-193, pp. 3007-3013, 2011.

[2] H. Taniguchi and S. Miyamae, "Power generation analysis for high-temperature gas turbine in thermodynamic process," Journal of Propulsion and Power, vol. 16, no. 4, pp. 557-561, 2000.

[3] A. Khaliq and S. C. Kaushik, "Thermodynamic performance evaluation of combustion gas turbine cogeneration system with reheat," Applied Thermal Engineering, vol. 24, no. 13, pp. 17851795, 2004.

[4] A. B. Keith and R. H. Kenneth, Economic optimization of natural gas processing plant including business aspects [Ph.D. dissertation], Texas A \& M University, 2006.

[5] K. L. Jibril, A. I. Al-Humaizi, A. A. Idriss, and A. A. Ibrahi, "Simulation of turbo-expander processes for recovering of natural gas liquids from natural gas," Saudi Aramco Journal of Technology, pp. 9-14, 2005.

[6] S. T. Donnelly, J. C. Polasek, and J. A. Bullin, Process Simulation and Optimization of Cryogenic Operations Using Multi-Stream Brazed Aluminium Exchangers, Bryan Research and Engineering, 2006.

[7] T. Ganapathy, N. Alagumurthi, R. P. Gakkhar, and K. Murugesan, "Exergy analysis of operating lignite fired thermal power plant," Journal of Engineering Science and Technology Review, vol. 2, no. 1, pp. 123-130, 2009.

[8] A. A. Ujile and L. Alawa, "Thermodynamic evaluation of a natural gas processing plant: case study-Obiafu/Obrikom, Rivers State, Nigeria," Journal of Advanced Science and Engineering Technology, vol. 2, no. 1, pp. 76-80, 2012.

[9] T. D. Eastop and A. McConkey, Applied Thermodynamics for Engineering Technologists, Pearson Education, 5th edition, 2005.

[10] Y. A. Cengel and M. A. Boles, Thermodynamics, an Engineering Approach, McGraw-Hill, New York, NY, USA, 4th edition, 2002.

[11] I. S. Stanley, Chemical, Biochemical, and Engineering Thermodynamics, John Wiley \& Sons, 4th edition, 2006.

[12] C. Arora, Refrigeration and Air Conditioning, McGraw Hill, Delhi, India, 5th edition, 2005.
[13] A. Kumar, S. S. Kachhwaha, and R. S. Mishra, "Thermodynamic analysis of a regenerative gas turbine cogeneration plant," Journal of Scientific and Industrial Research, vol. 69, no. 3, pp. 225-231, 2010.

[14] R. José and Simões-Moreira, "Thermal Power Plant Performance Analysis," 2012, http://www.springer.com/978-1-44712308-8. 

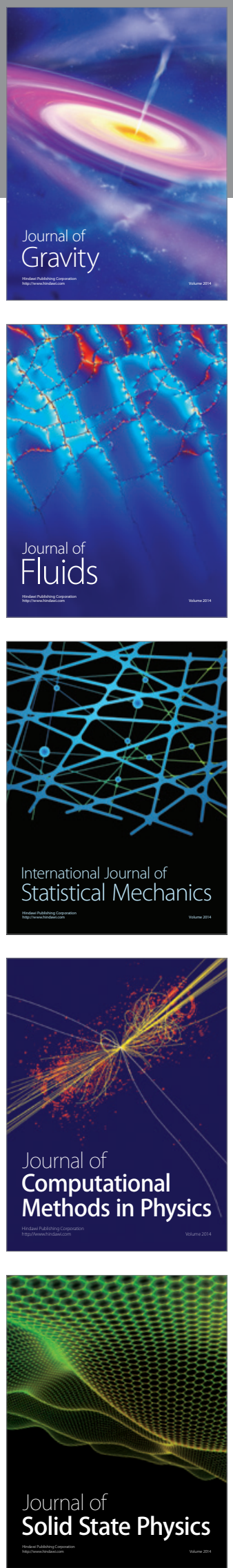

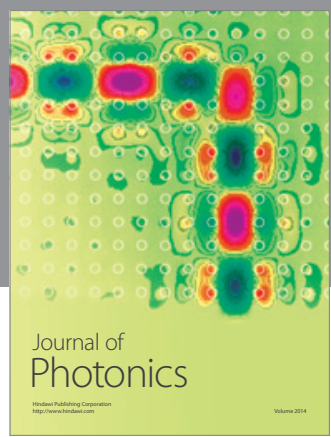

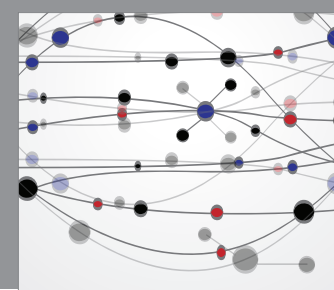

The Scientific World Journal

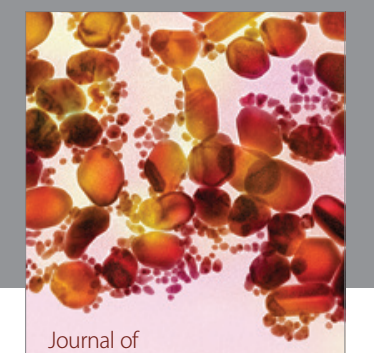

Soft Matter
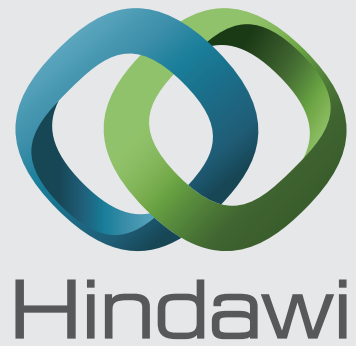

Submit your manuscripts at

http://www.hindawi.com
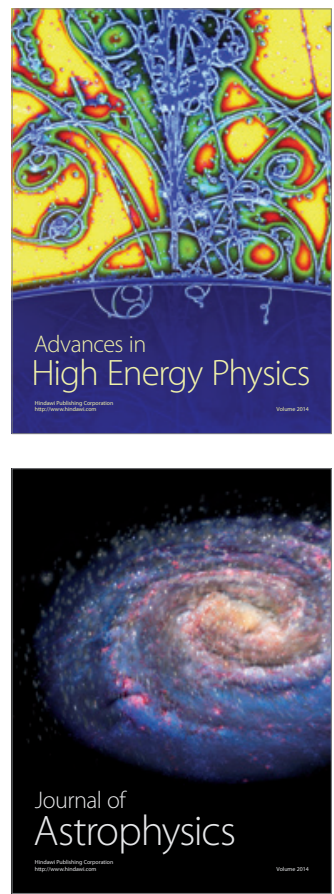
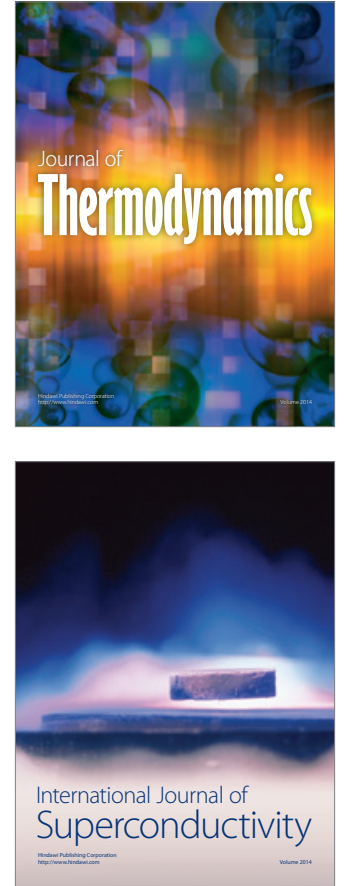
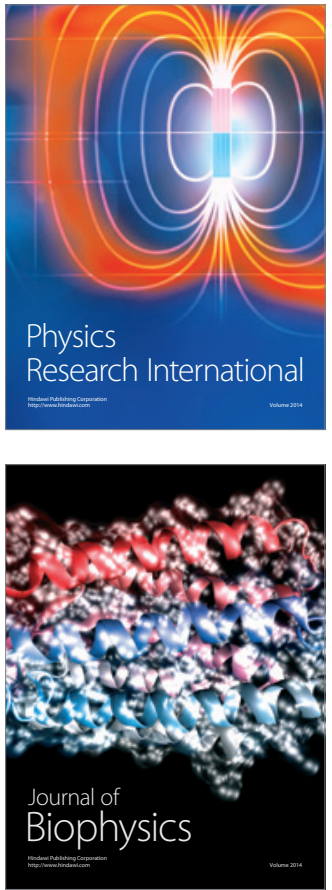
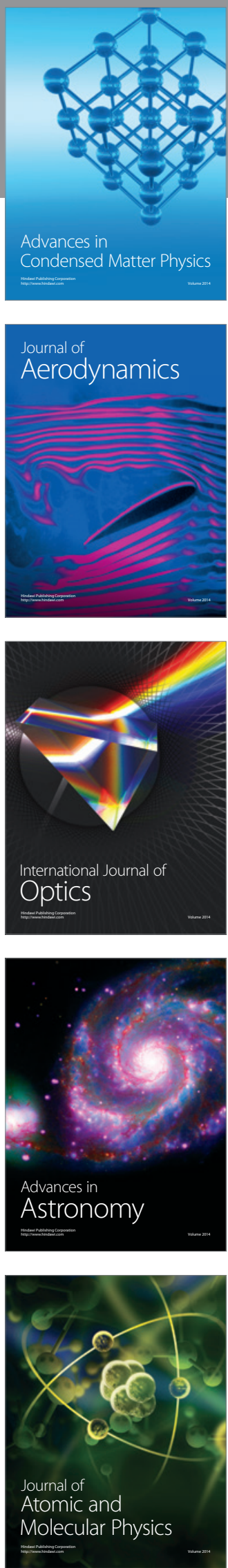